\title{
Empresarialismo, economía del suelo y grandes proyectos urbanos: el modelo de Puerto Madero en Buenos Aires
}

\section{Beatriz Cuenya}

Investigadora y Directora del Centro de Estudios Urbanos y Regionales CEURCONICET.

\section{Manuela Corral}

Tesista doctoral del Ministerio de Ciencia y Técnica en el CEUR.

RESUMEN | El empresarialismo constituye el eje de las políticas de regeneración urbana motorizadas a través de grandes proyectos que crean fragmentos exclusivos de la ciudad. Esta nueva forma de gobernanza ha tenido resultados exitosos y grandes fracasos, lo que alimenta un debate sobre cómo juzgarlos.

Este trabajo expone los principios del nuevo empresarialismo urbano, recogiendo los aportes de la literatura reciente sobre el tema. Luego postula que el fundamento que orienta el empresarialismo en los grandes proyectos se ubica en su proceso de producción: este exige una articulación entre actuaciones inmobiliarias, actuaciones urbanísticas y desarrollo constructivo, a cargo del sector público y los agentes privados, abriendo la posibilidad de crear y captar rentas y ganancias. A la luz de este marco analítico, se examina críticamente el proyecto Puerto Madero, buscando entender de qué manera se manifestó el empresarialismo y cuáles fueron sus implicancias sociales.

PALABRAS CLAVE | Renovación urbana, proyecto urbano, mercado inmobiliario.

ABSTRACT | Entrepreneurialism is one of the forms adopted by urban regeneration policies motorized through large urban projects that create unique pieces of the city. This new form of governance has had positive results and great failures, fueling a debate about how to judge them.

This paper outlines the principles of the new urban entrepreneurialism, collecting the contributions of the recent literature on the subject. Then it postulates that the key axis orienting entrepreneurialism in large projects is located in its production process: it requires joint action between real estate, urbanistic regulations and constructive development, in charge of public and private agents, opening the possibility of create and capture rents and profits. From this perspective the paper critically examines the Puerto Madero project, seeking to understand how entrepreneurialism is expressed and what are their social implications.

KEY WORDS | Urban renewal, urban project, real state market.

Recibido el 25 de octubre de 2010, aprobado el 18 de marzo de 2011.

Correspondencia: Saavedra 15, 6 Piso, (1083) Ciudad Autónoma de Buenos Aires, Argentina. Teléfono: (54 11) 49524222 ; 47713272.E-mail:beatrizcuenya@gmail.com|mail:manucoral@gmail.com 


\section{Introducción}

El empresarialismo constituye uno de los ejes reconocibles de las políticas de regeneración urbana motorizadas a través de grandes proyectos que crean fragmentos exclusivos de la ciudad. Esto se ha verificado en los países capitalistas avanzados desde la década de 1980 y en los países latinoamericanos desde la de 1990, bajo el influjo creciente de la globalización.

Se admite que el empresarialismo es una forma de regulación política y social que ha reflejado y acompañado los procesos de reestructuración de las economías capitalistas en las últimas décadas. En respuesta a la crisis del desarrollo fordista y de su Estado social keynesiano (desindustrialización, desempleo y austeridad presupuestaria fiscal), en muchas metrópolis del mundo se asistió a una ampliación del rol de los gobiernos locales, junto con una redefinición en las prioridades de las políticas urbanas. Estas políticas pasaron a asignar un rol protagónico al capital privado en el desarrollo urbano. La atracción de inversiones privadas se convirtió en un objetivo clave para contrarrestar la declinación económica de las ciudades y aumentar la base de sus recursos fiscales. En la fase de globalización contemporánea -ante patrones más flexibles y geográficamente móviles de acumulación del capital- se expandieron las estrategias urbanas orientadas a maximizar el atractivo del espacio local para el desarrollo capitalista y contribuir a su posicionamiento en el escenario mundial.

Los estudios sobre el tema muestran que esta nueva forma de gobernanza ha tenido resultados exitosos y grandes fracasos en los distintos campos de actuación pública en los que se ha aplicado, incluido el territorial. La diversidad de resultados, que incluso se combinan de modo contradictorio en algunas experiencias, alimenta un debate sobre cómo juzgarlos.

Este trabajo expone los principios y estrategias del nuevo empresarialismo urbano, recogiendo los aportes de la literatura reciente sobre el tema. Luego analiza de qué manera el empresarialismo se expresa en los grandes proyectos urbanos, identificando su rasgo más relevante. Se postula que el eje clave que orienta el empresarialismo en los grandes proyectos se ubica en su proceso de producción: este exige una articulación entre actuaciones inmobiliarias, actuaciones urbanísticas y desarrollo constructivo, a cargo del sector público y los agentes privados, abriendo la posibilidad de crear y captar rentas y ganancias A la luz de este marco analítico, se examina críticamente el proyecto Puerto Madero en la ciudad de Buenos Aires. Se intenta aportar elementos que permitan entender de qué manera se manifestó el empresarialismo en Puerto Madero y cuáles fueron sus implicancias sociales.

\section{El empresarialismo como eje de la política urbana}

Definido como "nuevo paradigma empresarial" en manos del sector público, el empresarialismo urbano expresa una nueva modalidad de gobernanza, que han 
adoptado autoridades locales de tendencias políticas diversas ${ }^{1}$ (Harvey, 1989, 2001; Cox, 1991; Borja y Castells, 1997; Rodríguez et al., 2001; OECD, 2007; De Mattos, 2009). En el campo de las políticas urbanas, eso ha significado un cambio más o menos drástico en las formas de intervención en la ciudad, desde las estrategias orientadas al ordenamiento territorial, la obra pública y la prestación de servicios de bienestar social a la ciudadanía, hacia el crecimiento económico, la asunción de riesgos, la innovación y una orientación al sector privado (Rodríguez, Moulanet y Swyngedow, 2001; OECD, 2007).

Tres principios básicos definen conceptualmente al empresarialismo urbano (Harvey, 1989):

Primero. Se promueve una alianza entre "sector público-sector privado", en la cual, el gobierno local es uno más de los múltiples agentes que intervienen en la escena urbana dominada por la influencia de coaliciones multiagentes y consorcios público-privados. La combinación de recursos privados con capacidades gubernamentales sirve para intentar atraer fuentes de financiamiento externo, nuevas inversiones directas, o nuevas fuentes de empleo.

Segundo. La actividad de esa alianza público-privada está orientada por una lógica empresarial. En tanto tal, es de ejecución y diseño especulativo, por lo que está sujeta a los peligros propios del desarrollo especulativo, a diferencia del desarrollo racionalmente planificado. El enfoque empresarial también refiere a una orientación "emprendedora" en el sentido de crear e identificar oportunidades innovadoras de inversión que el sector público asimila del mundo empresarial.

Tercero. El empresarialismo se centra más en la economía política del lugar y no en la del territorio. La construcción del lugar es entendida como el impulso de proyectos específicos locales (estadios deportivos, centros comerciales y de convenciones, o un centro cultural) que son una faceta de la estrategia de regeneración urbana; en tanto que la construcción del territorio involucra proyectos económicos de mayor alcance (como vivienda y educación, por ejemplo). Si bien, la construcción del lugar puede tener efectos a escala metropolitana (mejora en la base impositiva, circulación local de ingresos y creación de empleos) usualmente no aborda los problemas más amplios que aquejan a la región o al territorio en su totalidad.

Empíricamente, según Harvey, las ciudades del capitalismo avanzado han desplegado cuatro estrategias de empresarialismo urbano que también pueden encontrarse en muchas otras ciudades del mundo en desarrollo:

i La explotación de ventajas para la producción de mercancías y servicios, ya sea a través del aprovechamiento de recursos propios (por ejemplo petróleo), la facilidad de acceso a determinados mercados o las inversiones públicas y privadas en infraestructuras físicas y sociales que fortalecen la base económica regional.

ii La mejora de la posición competitiva relativa a la división espacial del consumo, para atraer a los consumidores con dinero, mediante inversiones cada vez

1 La gobernanza hace alusión al hecho de que el poder para gobernar la ciudad excede al gobierno urbano; incluye una coalición amplia de fuerzas movilizadas por diversos actores sociales (empresas industriales, comercios, promotores inmobiliarios, instituciones educativas y religiosas, sindicatos, partidos políticos, organizaciones sociales, aparatos estatales). 
más selectivas: innovación cultural, mejora física del entorno urbano, atracciones comerciales y para el ocio, el espectáculo y la exhibición, que constituyen ingredientes notables de la regeneración urbana.

iii La lucha para atraer funciones de control en las finanzas, comunicaciones y áreas de gobierno, a través de costosas infraestructuras en transporte, comunicaciones, espacios de oficinas altamente equipadas con tecnologías de punta y provistas de amplia gama de servicios de apoyo; todo ello para el logro de una "ciudad de la información".

iv La competencia por la captación y redistribución de excedentes y flujos de ayudas de parte de las administraciones centrales que, en muchos casos, contribuyen al sostén de la economía urbana en sectores como la salud y la educación, por ejemplo.

En la práctica, estas opciones se han presentado de manera combinada. Han mostrado la necesidad del empresarialismo urbano de articularse con constantes innovaciones de producción, de consumo, culturales, en el estilo de vida, las expresiones físicas, los productos y servicios e incluso las formas institucionales y políticas para poder operar en un contexto de fuerte competencia interurbana.

\section{Empresarialismo y grandes proyectos urbanos}

El empresarialismo urbano ha tenido impactos notables en el medio ambiente construido. Ha contribuido a producir nuevas configuraciones espaciales (también denominadas nuevas formas urbanas), entre las que se incluyen los espacios exclusivos de centralidad, construidos a través de grandes proyectos de renovación urbana. Estos grandes proyectos ejemplifican la estrategia empresarialista, que Harvey ha denominado "la construcción del lugar". Acá se expone una lógica pública que apunta a la competitividad mediante la revitalización de la vieja ciudad industrial, atrayendo inversiones y promoviendo asociaciones publico-privadas.

Los grandes proyectos urbanos se orientan a la transformación funcional y física de áreas estratégicas, que habían quedado relegadas por el declive de los usos funcionales otrora dinámicos en la etapa industrialista, para adaptarlas a los nuevos requerimientos de acumulación y consumo que plantea el capitalismo en su fase actual. Tales espacios (usualmente terrenos públicos ferroviarios y portuarios, áreas de depósitos y silos, terrenos para carga y de descarga, etc.) se reconvierten en ambientes construidos relumbrantes. Con diseños y tecnologías de vanguardia, alojan usos mixtos de alta gama -oficinas equipadas con tecnología de punta, hoteles para el turismo internacional, restaurantes y boutiques exclusivas, centros de cultura e innovación, complejos de viviendas con variedad de amenities- que atienden una demanda de alto poder adquisitivo que excede el ámbito local para incluir empresas, inversores y usuarios nacionales e internacionales (Cuenya, 2009a). También denominados "urbanizaciones sobresalientes", suele asignarse a estos proyectos el objetivo de mejorar la imagen de la ciudad y proyectarla como 
lugar atractivo para vivir, trabajar e invertir, incentivar el turismo y estimular su producción cultural (OEDC) ${ }^{2}$.

Además del principio de recomponer la imagen de la ciudad para atraer capitales (rasgo recurrentemente mencionado en la literatura sobre el tema), el eje clave y peculiar que orienta el empresarialismo en los grandes proyectos se ubica en el proceso de producción de esta nueva geografía urbana. Los grandes proyectos urbanos son una herramienta de creación y captación de rentas y ganancias, cuyo montaje exige una articulación entre actuaciones inmobiliarias, actuaciones urbanísticas y desarrollo constructivo, a cargo del sector público y los agentes privados. Hay un encadenamiento entre las siguientes cuatro operaciones: i) el fraccionamiento de grandes extensiones de tierras públicas desnudas o casi vacantes, ii) la comercialización de las parcelas resultantes bajo nuevas normas urbanísticas, iii) la construcción de edificios de alta gama y iv) la posterior venta de los inmuebles a usuarios de elevado poder adquisitivo. La naturaleza de estas actividades y su encadenamiento abren al sector público y a los agentes privados involucrados la posibilidad de capturar las plusvalías y ganancias que se generan, precisamente, por efecto de los cambios urbanísticos notables que tienen lugar en el área.

Desde cierta óptica, la combinación de recursos públicos y capitales privados es considerada una estrategia empresarial innovadora a la que acude el sector público para financiar el desarrollo urbano en épocas de crisis presupuestaria. Pero también es claramente una estrategia especulativa.

Como advierten los expertos en el mercado del suelo urbano, cuando los terrenos pasan de un uso a otro que es superior y/o aumentan su capacidad de edificación, suben rápidamente sus precios y se crean las condiciones propicias para prácticas especulativas orientadas a capturar esos incrementos de valor del suelo ${ }^{3}$. Dos tipos de prácticas especulativas pueden ponerse en práctica en los grandes proyectos urbanos: la "especulación pasiva", también llamada "especulación del suelo", y la "especulación inductiva" o "especulación inmobiliaria" (Jaramillo, 2003; Topalov, 1984). La primera es ejercida por los propietarios del suelo, que disponen el suelo (o lo compran) antes de que se generen los aumentos de precios y, sin realizar ninguna acción productiva, lo venden luego, apropiándose de las plusvalías. En los grandes proyectos el primer rol corresponde típicamente al Estado nacional en tanto propietario mayoritario de grandes extensiones de tierras que quedaron desafectadas de sus usos previos (ferrocarriles y puertos) y que se ponen a la venta para usos jerárquicos. El otro tipo de especulación es ejercida por actores capaces

2 Al igual que el propio empresarialismo, los grandes proyectos responden a procesos socioeconómicos más amplios que se han verificado a escala planetaria en los últimos treinta años, entre los cuales nos parece relevante resaltar: i) los requerimientos funcionales y de aglomeración en espacios estratégicos por parte de las empresas líderes vinculadas a los sectores más activos e internacionalizados de la economía urbana; ii) las demandas de calidad de vida, confort, exclusividad y autosegregación por parte de la elite ganadora de la nueva economía (cuadros gerenciales y tecnocráticos de las empresas líderes allí localizadas, turismo internacional, usuarios locales de altos ingresos); iii) la creciente avidez por parte de capitales altamente especulativos que consideran a la tierra como un medio privilegiado para su valorización.

3 Según Jaramillo (2003), estos incrementos en los valores del suelo suelen darse precisamente en el tiempo en el que tienen lugar los cambios urbanísticos, ya que probablemente después los incrementos siguen la tendencia general de los precios. 
de generar externalidades que inciden en el precio del suelo dentro de ese espacio. Esta especulación es típicamente ejercida por dos tipos de agentes: i) los promotores/desarrolladores que compran el suelo a precios de un uso que arroja rentas moderadas y luego de su acción transformadora venden el espacio construido con los precios que corresponden a ese nuevo uso jerarquizado, es decir, con rentas superiores (Jaramillo, 2003, p. 59) ${ }^{4}$; ii) el gobierno local, que invierte en obras de infraestructura para acondicionar el suelo y aprueba normativas asignando nuevos usos y coeficientes constructivos.

El Estado despliega los dos tipos de especulación que afectan al mercado del suelo. Sin embargo, hay una distinción que es muy importante advertir: los distintos roles que cumplen el Estado nacional-propietario y el Estado local-promotorregulador condicionan la legitimidad de las políticas que se llevan adelante. Hay un consenso bastante amplio entre especialistas y académicos en este sentido: mientras las prácticas especulativas de propietarios pasivos deben ser penalizadas, inhibidas y/o grabadas fiscalmente, las actuaciones públicas del gobierno local invirtiendo en obras de infraestructura y aprobando normativas urbanas que valorizan el suelo deben tener una contraparte fiscal que puede y debe ser utilizada en beneficio de la comunidad. Las herramientas de captura de plusvalías, contempladas en las legislaciones más avanzadas de América Latina (como en Brasil y Colombia) se apoyan precisamente en la idea de que el gobierno local debe recuperar en beneficio de la comunidad al menos una parte de los beneficios que capturan los terrenos por efectos de obras públicas y normativa urbana. Los grandes proyectos ponen a la luz la paradoja de que sea el sector público el que cumpla estos dos roles.

En suma, el patrón de producción de grandes proyectos urbanos -en el que se conjugan de modo complejo los principios del urbanismo y del desarrollo inmobiliario- contiene los tres rasgos que conceptualmente definen al empresarialismo, según Harvey: la alianza entre el sector público y el sector privado; empleo de una lógica especulativa por parte del sector público y el privilegio de iniciativas centradas en el lugar. A esto se asocian otros elementos que también caracterizan la estrategia pública empresarial, tales como: el modo corporativista de tomar las decisiones, así como también la falta de transparencia en los procedimientos y en las rendiciones de cuentas.

\section{Puerto Madero: perfil de un barrio brillante}

Puerto Madero implicó la refuncionalización y comercialización de tierras públicas estratégicas, junto con la atracción de inversionistas privados y empresas desarrolladoras que compraron suelo y construyeron sobre él un entorno de nivel premium dirigido a usuarios corporativos e individuales de alto poder adquisitivo. La reurba-

Los desarrolladores combinan estrategias de capitalista productor (búsqueda de ganancia productiva), con la de especulador (captura de los incrementos de los precios de los terrenos), puesto que el capitalista constructor se transforma también en propietario al menos mientras dura el proceso de construcción de la obra. 
nización comprendió 170 hectáreas en un área portuaria fuera de actividad, lindante con el centro administrativo y financiero, incluyendo un conjunto de 16 edificios degradados pero de alto valor patrimonial que son los antiguos docks del puerto 5 . En la Figura 1 se observa el mapa de la zona. El proyecto fue iniciado en 1989 y se desarroló en dos etapas, de acuerdo a un Master Plan que orientó la urbanización del área.

\section{Figura 1| Mapa de Puerto Madero}

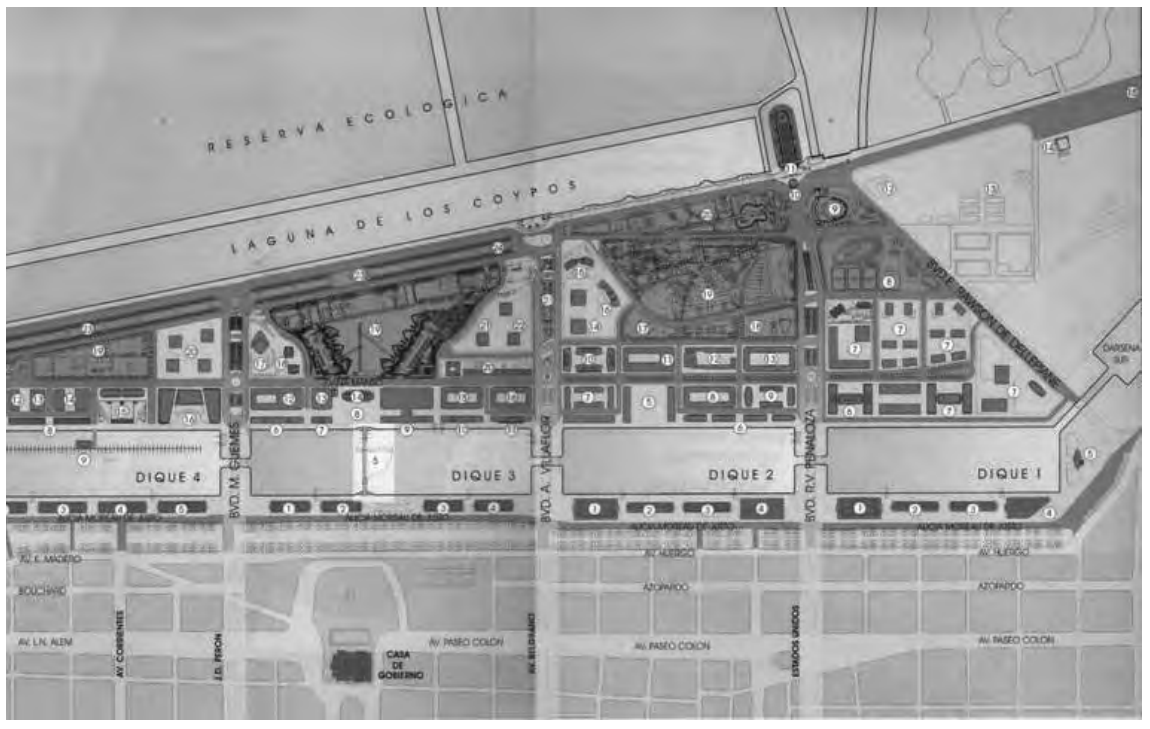

Fuente Corporación Puerto Madero.

Hacia mediados de 2009, luego de 20 años de desarrollo, y cuando aún faltaba urbanizar algunos predios del lado este, la superficie construida había alcanzado los 2,3 millones de metros cuadrados; la población estable rondaba las 16 mil personas y la inversión total, pública y privada, alcanzaba 1.700 millones de dólares, estimándose que una vez finalizado el proyecto esta cifra llegará a 2.500 millones de dólares. El valor promedio en dólares de nuevos emprendimientos ha tenido un constante incremento. Y el valor de venta en dólares de departamentos ubica al barrio en el segundo lugar después del super exclusivo barrio Palermo Chico. Las figuras 2, 3 y 4 a continuación ilustran el progreso en la evolución histórica de algunos de estos indicadores.

5 Puerto Madero tiene una extensión mayor que los Water Front de Barcelona (79 has), Baltimore ( 96 has) y Boston (41,5 has). Pero es menor que los Docklands de Londres (1.200 has) (Etulain, 2009). 
FIGURA 2 | Serie histórica de la construcción en Puerto Madero

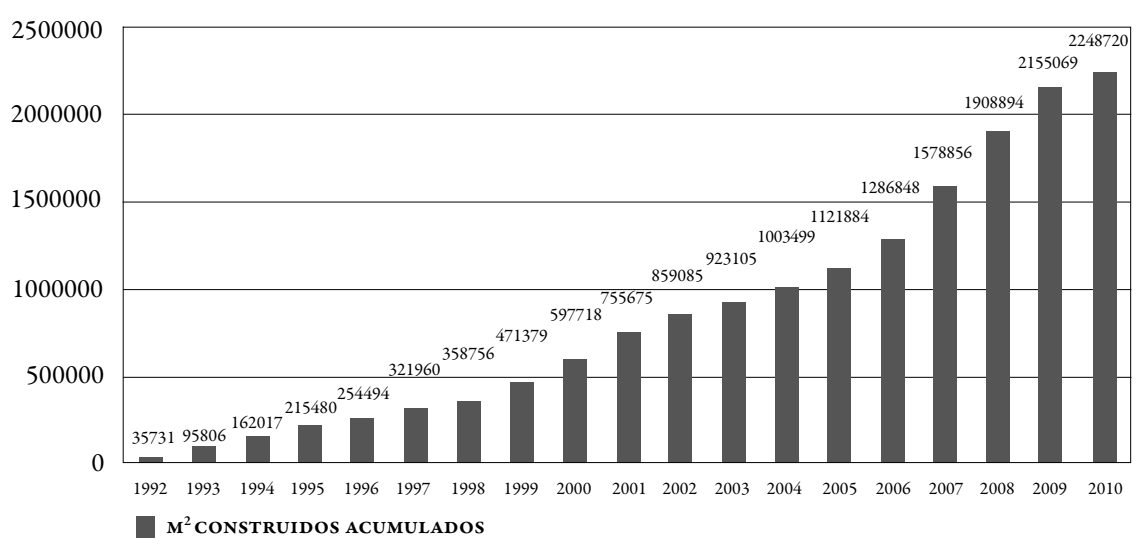

FUENTE L.J. RAMOS BROKERS INMOBILIARIOS (2009).

FIgURA 3 |Variación de valores en dólares de nuevos emprendimientos en Puerto Madero

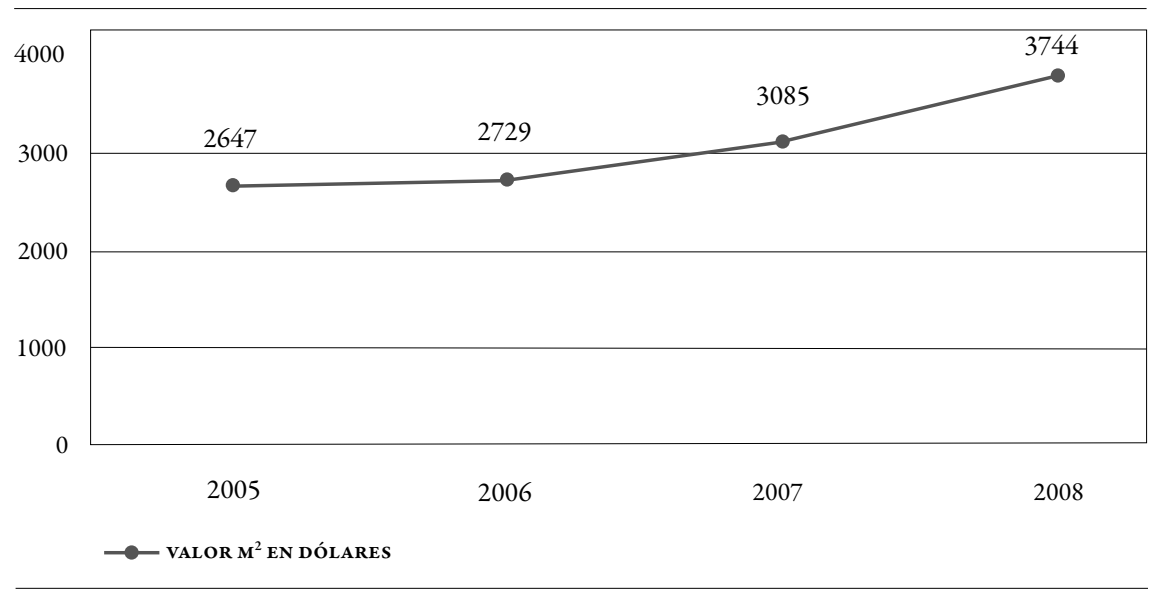

FUENTE L.J. RAMOS BRoKers INMOBILIARIOS (2009).

A veinte años de gestación del proyecto, Puerto Madero es exhibido como un éxito por su impulsores, no sólo porque logró concretarse, atrayendo inversiones millonarias a pesar de la crisis económica argentina de 2001-2003 y de la posterior crisis financiera internacional de 2008. También, porque pasó a ser considerado como un nuevo símbolo de la ciudad que coloca a Buenos Aires al nivel de otras metrópolis mundiales.

El proyecto ha sido valorado internacionalmente en el marco de la $9^{a}$ Muestra Internacional de Arquitectura de la Bienal de Venecia. La Región del Veneto premió la reconversión del área Puerto Madero, reconociendo el modelo de gestión llevado adelante, en el que confluyeron los esfuerzos de los Estados nacional y local, junto con el sector privado. 
FIgURA 4 | Valor máximo y promedio de venta de departamentos en Puerto Madero y otros barrios de la ciudad de Buenos Aires en 2009

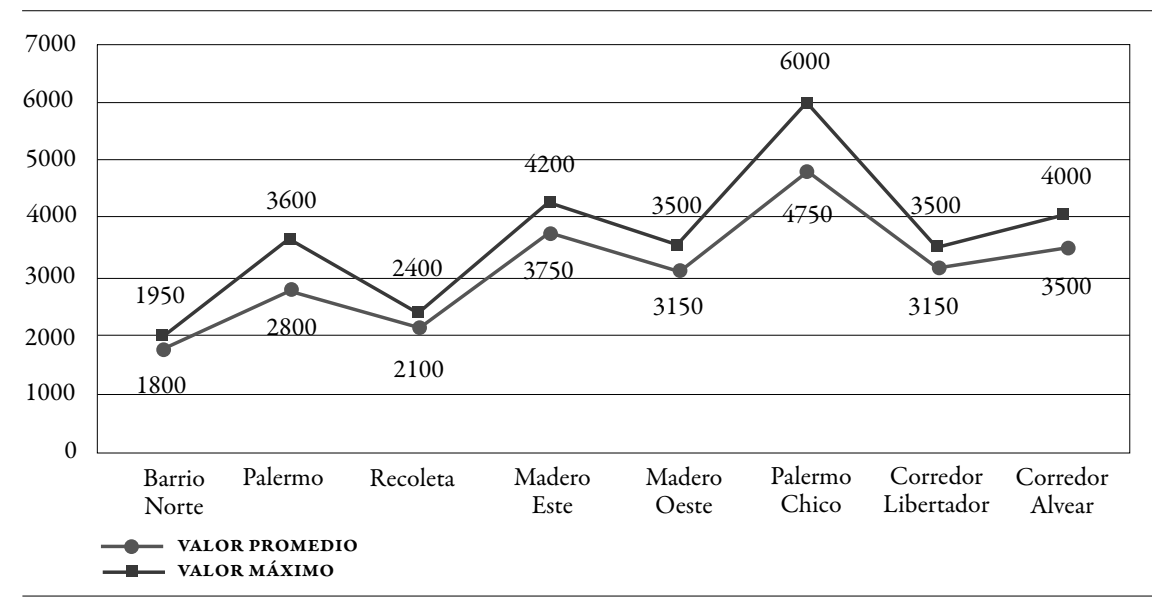

FUENTE L.J. RAMOS BROKERS INMOBILIARIOS (2009).

Los analistas del mercado inmobiliario se sumaron al homenaje a Puerto Madero. La empresa inmobiliaria L.J. Ramos elaboró un interesante y sustancial informe, denominado La segunda globalización en Buenos Aires, en el cual presenta al nuevo barrio bajo este lema: Perfil de un joven brillante:

El nuevo barrio se ha convertido en un símbolo de poder y dinero: un lugar al que muchos miran como una aspiración, una meta a conseguir y que algunos critican ácidamente desde perspectivas en general ideológicas. En su look de primer mundo penetran a veces realidades que recuerdan a problemáticas propias de Latinoamérica (como la proximidad de una villa de emergencia, o las aglomeraciones de puestos de venta informal en la Costanera Sur durante los fines de semana). Pero en la mayor parte de su extensión Puerto Madero luce atractivo y fotogénico, como una estrella de cine llena de glamour." (Ramos, 2009).

Sin el ánimo de hacer un cuestionamiento ideológico al proyecto, como el que censuran los Brokers inmobiliarios, el análisis crítico que desarrollamos a continuación intenta ser un aporte saludable para balancear en su justa medida las dimensiones que aparecen tan valoradas cuando se mira sólo lo que brilla.

\section{La Corporación Puerto Madero y la lógica empresarial del Estado}

\section{La asociación público-privada en el seno del propio Estado: la Corporación}

\section{Puerto Madero}

Una de las facetas del empresarialismo urbano, como se ha señalado, es la alianza sector público-sector privado. En Puerto Madero esa alianza no se presentó como en otros países, donde los capitales locales se asocian y/o presionan al gobierno de la ciudad para atraer inversiones externas, capaces de dinamizar la base económica 
y crear empleo. Acá, la amalgama publico-privado se produjo, en primera instancia, en el seno del propio Estado. Se trata, sin dudas, de una innovación político institucional en el contexto argentino, que consistió en la creación de la Corporación Antiguo Puerto Madero SA, concebida como una empresa urbanizadora estatal, bajo la forma de una sociedad anónima, que se rige por las leyes del derecho privado ${ }^{6}$.

Eso significa que las actividades de la Corporación están reguladas por una ley nacional que controla a las sociedades comerciales privadas ${ }^{7}$. No le corresponden de manera automática a la Corporación las normas sobre gestión ni los sistemas de control de la administración pública. Es decir, que la Corporación no está obligada a informar sobre el manejo de sus recursos. Es competencia de la asamblea de socios (el órgano de gobierno) la decisión de que se efectúe tal control. Sin embargo, según el último informe de relevamiento efectuado por la Auditoría General de la Ciudad Autónoma de Buenos Aires en $2003^{8}$, "por no haberse adoptado tal decisión asamblearia, las disposiciones sobre Administración Financiera y de los Sistemas de Control del Sector Público Nacional, previstas en la Ley 24.156, no resultan de aplicación obligatoria a la Corporación" (AGCBA, Informe de relevamiento de 2005). Sus estados contables se encuentran auditados por estudios contables privados desde 1997.

Las debilidades derivadas de este esquema, así como la sugerencia de readaptarlo a las nuevas circunstancias políticas, económicas y sociales presentes al inicio de la nueva década del 2000 son advertidas por los auditores en el mencionado informe. Tres señalamientos apuntan en esa dirección: a) la necesidad de ejercer un control más directo sobre la gestión de la Corporación Puerto Madero, promoviéndose para eso la aplicación de las disposiciones sobre administración financiera y los sistemas de control del sector público nacional; b) la necesidad de generar canales formales de comunicación y colaboración entre los organismos de control, de modo de garantizar el adecuado seguimiento de las actividades y fines societarios; y c) la necesidad de subsanar la falta de presentación de los estados contables ante la Inspección General de Justicia del ejercicio económico de 2003. Cabe aclarar que, luego de un largo vacío, los últimos balances fueron subidos al sitio web de la Corporación.

Lejos de esta readecuación a la tutela estatal, después de haber vendido la totalidad de sus activos (los docks y los terrenos) hacia fines de 1990 la Corporación

6 Enmarcada en el proceso de reforma del Estado y en las leyes de emergencia administrativa vigentes en la década neoliberal de 1990, la Corporación Antiguo Puerto Madero se creó por un decreto del Poder Ejecutivo Nacional (Decreto 1279 de 21 de noviembre de 1989) y no por una ley del Congreso. El Decreto incluye: a) un Convenio de constitución de la Corporación suscripto entre el Ministerio de Obras y Servicios Públicos y la Municipalidad, b) el Decreto Municipal 2587/89 y c) El Estatuto social de la Corporación. Sus únicos accionistas en partes iguales son el gobierno nacional y el gobierno de la ex municipalidad de Buenos Aires (hoy Ciudad Autónoma de Buenos Aires). El capital social inicial de la Corporación se conformó, en un $50 \%$, con la transferencia en propiedad de las tierras que pertenecían al Estado nacional: las 170 has de tierras a urbanizar incluidos 16 Docks. El 50\% restante fue aportado por la ciudad y consistió en "los aportes de obra intelectual" de sus organismos, entendiéndose por tal la experiencia para llevar a cabo la operación y la capacidad de valorizar el suelo derivada de la atribución municipal sobre la normativa urbana.

7 Las actividades de la Corporación están reguladas por la Ley 19.550 que controla a las sociedades comerciales privadas.

8 La Auditoría General de la CABA depende de la legislatura. Ejerce su competencia sobre el sector público centralizado y descentralizado, empresas, sociedades o entes en los que la ciudad tenga participación. (Informe de relevamiento, CABA, marzo de 2005). 
prácticamente se transformó en una empresa privada que compite en el mercado con otras promotoras o desarrolladoras, y que además exporta su know how fuera de la ciudad y del país. Efectivamente, en 1999 la Corporación modificó su estatuto original de constitución. El objeto de acción de la empresa pasó a incluir la urbanización de áreas dentro y fuera de la Republica Argentina (recién en 2008 se anunciaron nuevos proyectos). Y fue autorizada a operar como inmobiliaria, constructora, desarrolladora, urbanizadora, asesora, Project manager, fiduciaria, directora de obra, auditora, administradora fiduciaria e inversora. Para ello se le permite:

asociarse bajo cualquier forma, adquirir o trasmitir bienes a cualquier título que fuere incluso al fiduciario, dar o tomar en leasing, realizar la prestación de todo tipo de servicios, asesoramiento, de transferencia de tecnología, gerenciamiento de proyectos, supervisión, dirección de obra, auditoría, locación de obras, operaciones financieras y de inversión, proyectos y construcciones de toda clase (...) administrar bienes o fondos propios o ajenos, construir, reciclar, remodelar, recuperar, etc... (Auditoría General de la CABA. Informe de relevamiento Corporación Antiguo Puerto Madero SA, 2003)'.

\section{La promoción económica del lugar sin redistribución del excedente}

La ingeniería constitutiva de la Corporación tuvo otra implicancia clave desde el punto de vista del cariz empresarialista de la política urbana implementada, una gradual subordinación de algunos propósitos urbanísticos legítimos planteados originalmente.

En su etapa fundacional, la operación Puerto Madero se propuso dos objetivos: a) el rescate urbanístico del área céntrica de la ciudad, evitando un eventual deterioro urbano y la pérdida de valor, procesos ocurridos en otras ciudades del mundo con puertos en declive, b) la búsqueda de inversiones privadas que hicieran viable la revitalización del área (además de promover el desarrollo de nuevas actividades económicas y generar empleo) en un contexto de crisis económica y ausencia de recursos públicos para ese fin (Garay, 2001).

Para eso, la Corporación se creó con el objeto de llevar adelante un proyecto de urbanización en el área de Puerto Madero, ajustándose a un Master Plan definido en 1992 y que orienta los parámetros urbanísticos para el desarrollo del área. Los recursos con que se dotó a la Corporación (de acuerdo al Estatuto de funcionamiento) se componían, además del capital social inicial, de los dividendos derivados de la explotación de sus bienes ${ }^{10}$. La sociedad fue autorizada a emitir acciones para incorporar capitales privados, nacionales o extranjeros, conforme las leyes de la Nación. Fue también autorizada a "vender, conceder, permutar, arrendar, total o parcialmente los inmuebles incorporados a su propiedad” (Decreto de creación).

9 Los proyectos desarrollados desde 1999 son: Proyecto ferro urbanístico en la Provincia de Mendoza; Convenio Marco con el Ente Binacional Yaciretá; Plataforma Intermodal de Transporte de Pasajeros Retiro 2010; y Plan Urbano en la ciudad de Barranquilla, Colombia. (Informe de Auditores Independientes Becher y Asociados, 2009).

10 De acuerdo al Estatuto de constitución, los dividendos de la Corporación se componen de: a) los honorarios que perciba por tareas de asesoramiento e información que brinde a terceros en cuestiones vinculadas a su objeto; b) los fondos de reserva que se creen con el producido de las actividades societarias; c) el producido de la venta, locación, usufructo, y toda forma de explotación de sus bienes; d) donaciones o legados, y e) todo otro recurso lícito (Art. 9). 
Dicho de otro modo: como la sociedad no tuvo ni tiene partidas presupuestarias asignadas, el plan de urbanización debió realizarse con los fondos procedentes de la venta de las 170 hectáreas de suelo y los 16 docks que fueron cedidos en propiedad a la Corporación por el Estado nacional.

Pero los objetivos urbanísticos y económicos planteados inicialmente no se limitaron a la construcción de las infraestructuras, equipamientos, espacios públicos, financiamiento de la promoción del proyecto y del funcionamiento de la Corporación, tal como fue oficialmente estipulado. Al finalizar la etapa operativa, la Corporación debía girar las ganancias de la operación a cada uno de los socios: el municipio y el gobierno nacional. La idea central fue realizar la operación urbanística "sin incorporar costos al Estado, proponiendo en cambio transferir los beneficios (calculados en un principio en 150 millones de dólares) que a su vez podrían en el futuro financiar otras operaciones de urbanismo" (Garay, 2001, p. 8).

Efectivamente, el Estatuto de la Corporación estableció que los dividendos debían ser pagados a los dos socios en proporción a las respectivas integraciones ${ }^{11}$. Si bien no fue posible conocer qué destino le asignó a dichas utilidades el Estado nacional (representado por el Ministerio de Obras Públicas y el Ministerio del Interior), en su momento, la municipalidad resolvió asignar sus dividendos a planes de vivienda (50\%), obras en educación (23\%) y en la reserva ecológica (2\%) (O:M. 44.945 de 1991; Art 12).

A más de veinte años de actividad de la Corporación, es posible afirmar que este propósito original de redistribuir los beneficios hacia otras áreas sociales -lo que hubiera permitido superar el limitado enfoque de promoción del "lugar" para aproximarse a una más legítima la promoción del “territorio" - no se cumplió. Esto fue reconocido por el propio mentor de Puerto Madero, el arquitecto Garay, para quien esa es una asignatura pendiente de gran relevancia que define la legitimidad de la operación ${ }^{12}$. Después del quinto año, en que comenzaría a equilibrarse el flujo de caja, según Garay:

... la Corporación debió girar recursos al gobierno nacional y al gobierno de la ciudad. En los hechos esos giros se han ido demorando, existiendo la tendencia a reemplazarlos por montos de obras. La cuenta especial abierta en el municipio fue abandonada en los presupuestos desde 1994 y lo que queda por cobrar difícilmente cubra los comprometidos 100 millones de dólares (Entrevista http://www. nuevomadero.com/esp/vivir...id_noticia=430).

De esa declaración podría inferirse que la razón por la cual no se giraron, ni redistribuyeron socialmente los dividendos obedece al hecho de que, luego de financiar la infraestructura, los gastos operativos de la Corporación y los del mantenimiento del nuevo barrio no quedaron dividendos excedentes para girar a los socios. Es difícil corroborar esta hipótesis dados los escasos datos disponibles.

11 La distribución de las utilidades que resultaran debían destinarse a: a) cinco por ciento (5\%) para un fondo de reserva legal hasta completar el veinte por ciento $(20 \%)$ del capital social, y b) el saldo tendrá el destino que decida la asamblea.

12 Entrevista a Alfredo Garay: http://www.nuevomadero.com/esp/vivir...id_noticia $=430$ 
Según una evaluación de resultados realizada por Garay (Cuadro 1) en base a los balances de la Corporación (1999 y 2000) y a una previsión de gastos, para el 2002 la operación debía arrojar dividendos que rondaban los 150 millones de dólares. Esto es, un 6 por ciento en relación a los 2.500 millones de dólares que representará Puerto Madero una vez finalizado el proyecto.

CUADRo 1 | Evaluación de ingresos, gastos y saldo en Puerto Madero

\begin{tabular}{l|c}
\hline EvAlUACión DE RESULTADOS (AL 1/1/2002) & U\$S \\
\hline Ingresos por ventas efectivizados al 2001 & 240.000 .000 \\
Gastos, infraestructura y equipamiento & 74.620 .000 \\
Gastos corrientes (estimado 10 años) & 101.680 .000 \\
\hline SALDo & $\mathbf{1 5 3 . 7 0 0 . 0 0 0}$ \\
\hline
\end{tabular}

FUENTE GARAY, 2001.

Sin embargo, según el Informe de la Auditoría de 2005, el análisis de trece años de ejercicio de la Corporación visto a través de los balances desde 1990 a 2002 reflejó una "pérdida del ejercicio de 99 millones de pesos, siendo la principal causa del quebranto los ajustes contables efectuados por efecto de la inflación, los que junto a los resultados financieros y por tenencia arrojan una pérdida de 69 millones de pesos" (AGCBA, 2005).

El último balance de la Corporación de 2009 muestra nuevamente un modesto saldo positivo de 15 millones de pesos (unos 5 millones de dólares), cifra que dista de los 150 previstos en la primera evaluación mencionada.

\section{El carácter especulativo de la operación urbanistica}

Tal vez el rasgo que más distingue a Puerto Madero (como a otros proyectos de su tipo) de otras grandes obras públicas del pasado es la aplicación por parte del sector público de una lógica empresarial especulativa, especialmente en el manejo del suelo urbano.

Actuando simultáneamente como propietario del suelo y como promotor inmobiliario, la Corporación ha desplegado una estrategia de venta controlada del suelo, promoviendo y autorizando el cambio de usos, y financiando parcialmente la operación mediante la construcción de infraestructura y servicios básicos (calles, redes de agua, cloacas, electricidad y gas). La combinación de estos roles le ha permitido ir poniendo en valor la tierra desnuda y desplegar con éxito una lógica de especulación pasiva e inductiva.

El rol de propietario-comercializador mayorista de suelo le permitió a la Corporación concentrar el poder de la operación y captar las plusvalías derivadas de la valorización progresiva de los predios; valorización que fue ocurriendo a medida 
que el área fue recibiendo inversiones públicas y privadas, y a medida que nuevos desarrolladores de peso y usuarios de altos ingresos fueron atraídos al área. La venta controlada de suelo es de hecho una estrategia común entre los promotores privados. Y consiste precisamente en reservar para el final la venta de la mejor parcela.

En base a esa figura, la Corporación pudo

...definir dónde comenzaría a venderse la tierra, priorizar terrenos que no eran los mejores ubicados, promover el desarrollo de partes atractivas del programa (aquellas con mayor demanda) y fijar tiempos para la realización de las edificaciones, evitando que inversores especulativos se posicionaran sobre parcelas que mantendrían baldías (Garay, 2001).

Varias condiciones debieron cumplirse para llevar adelante ese esquema: i) debió evitarse la venta en bloque del paquete accionario (las tierras) a los grandes empresarios privados de capital extranjero, que se mostraron interesados en la operación, y presionaron para lograr una compra de suelo en gran escala (y se sobreentiende que a un precio moderado acorde con su uso inicial descapitalizado); ii) hubo que garantizar que las infraestructuras se construyeran en tiempo y forma logrando así la credibilidad de los inversores ${ }^{13}$; iii) debió hacerse una cuidadosa programación del flujo de caja para que las obras pudieran financiarse con los anticipos de las ventas de suelo. Finalmente, se tuvo que definir el perfil de los inversores a quienes atraer, identificando no a los compradores de viviendas u oficinas, sino a los potenciales compradores de suelo dispuestos a construir sobre él. Es decir: desarrolladores-constructores de edificios.

Paralelamente a estos roles de propietario y promotor inmobiliario, la Corporación cumplió también un papel de controlador de la especulación privada. Al menos en la primera ronda de ventas de terrenos tuvo la necesidad y atribución de fijar restricciones a los desarrolladores privados antes de venderles el suelo. Para ello, el estatuto de creación de la Corporación estableció plazos estrictos de ejecución de las obras para evitar justamente que se formara un mercado de compra-venta de suelo y que los terrenos se mantuvieran baldíos a la espera de una mayor valorización. Ese control, sin embargo, no se mantuvo en el tiempo como se verá en el punto siguiente.

\section{La promoción inmobiliaria privada en Puerto Madero}

\section{La especulación de suelo}

La especulación de suelo fue una práctica también ejercida por agentes privados, a pesar de la intención inicial de la Corporación de evitarla.

En el transcurso de quince años, el proceso de compra-venta de suelo desnudo en el Dique 1 no sólo permite ilustrar la veloz valorización del suelo ante el avance

13 La Corporación realiza también una actividad constructiva (directa) a través de terceros: la construcción de infraestructura y provisión de servicios. El proyecto general de las obras de infraestructura fue licitado y contratado a Latinoconsut Constructora que desarrolló el proyecto de ingeniería. Las obras fueron licitadas por tramos, acompañando el proceso de venta de las tierras. Los pagos de adelantos y cuotas de los compradores de suelo garantizaron un adecuado flujo de caja que permitió el avance de las obras de infraestructura. 
de la urbanización del barrio, sino que también saca a la luz la notable trayectoria de algunos desarrolladores, como la empresa Newside. Esta empresa compró tempranamente en 1993 la totalidad de las tierras del Dique 1 (20 hectáreas) por 9 millones de dólares. Fue vendiéndolas por partes: parcelas 4 y 5 (3 millones); parcela 10 (10,5 millones) y parcelas 1,2 y 3 (40 millones). Al cabo de doce años, por la venta de estas tres parcelas, que representan el $30 \%$ de total del predio, obtuvo poco más de 53 millones de dólares. Luego de la última venta, la empresa logró adquirir el capital necesario para desarrollar uno de los proyectos edilicios más ambiciosos de Puerto Madero, denominado Madero Harbour. En esta última etapa, la firma Newside cambió su nombre por GNVGroup, cuando una de las familias propietarias adquirió la totalidad de las acciones que anteriormente compartía Newside con otros socios.

La segunda ronda de ventas en el Dique 1 muestra también el extraordinario rédito que implicó la economía del suelo. Las parcelas 4 y 5 , vendidas por 3 millones de dólares en el 2001, al cabo de apenas 3 años, fueron revendidas por el nuevo propietario al triple de ese valor. Se trató de un incremento solamente del componente suelo (plusvalías urbanas), ya que no se realizó ninguna inversión en el terreno. Eso muestra además que, en el transcurso de una década, esas parcelas de menos de una hectárea de suelo fueron vendida al mismo precio (9 millones de dólares) al que habían sido vendidas las 20 hectáreas que componen todo el dique en 1993.

La evolución de las operaciones de compraventa de suelo en el Dique 1 fue volcada en el Cuadro 2 presentado a continuación. El proceso se reconstruyó a partir de información periodística, contrastada con la cartografía del área. Dada la naturaleza de las fuentes de información, es posible que los valores no reflejen con exactitud los precios realmente pactados. De todos modos, son suficientemente contundentes como para consignar las tendencias antes señaladas. Más adelante, en el recuadro se describe el detalle de las transacciones realizadas, con indicación de las empresas que intervinieron, los montos declarados y el destino de los predios, en los casos que corresponde.

\section{CUADro 2 | Compra venta de suelo en el Dique 1 de Puerto Madero}

\section{Compra venta de suelo en el Dique 1 en Puerto Madero}

Hacia 1993, cuando todavía se encontraban en proceso de licitación los docks del sector oeste (sector por donde se inició la operación de urbanización) la Corporación vendió la totalidad de las parcelas de dicho dique a la empresa desarrolladora Newside S.A, (por un precio de 9 millones de dólares). (Reporte Inmobiliario, 18/03/2010). La venta en bloque de las 20 hectáreas de ese suelo estuvo atada a la propuesta de construir un predio ferial, contemplado en el Master Plan. Sin embargo, variados conflictos trabaron el comienzo de las obras, por lo cual, la mayor parte de las parcelas que componen el Dique 1 fueron revendidas a nuevos desarrolladores, algunas en más de una oportunidad.

Parcelas 4 y 5. En el año 2001, las parcelas 4 y 5 del Dique $1\left(8.000 \mathrm{~m}^{2}\right)$ fueron vendidas por Newside a la constructora Skanka por un valor aproxi- 
mado de 3 millones de dólares. (Diario Clarín, 13/07/2001). En el 2004 se produjo una reventa del predio al grupo mexicano IQ, por un valor de 9 millones de dólares (Diario El Cronista versión digital). Si bien en 2008 se promocionó la construcción de un hotel, hasta un año más tarde aún no se había comenzado a construir nada. (Diario La Nación, Se demoran inversiones en turismo, 15/9/2009). Lo interesante de notar es que, en el transcurso de diez años, una hectárea de suelo se vendió al mismo valor que las 20 hectáreas que componen el dique.

Parcela 10. Hacia 2005 la parcela 10 del Dique $1\left(20.000 \mathrm{~m}^{2}\right)$ se vendió a la desarrolladora G\&D por un precio de 10,5 millones de dólares. Esta desarrolladora, en asociación con el Grupo Farallón, planificó el proyecto denominado +5411 (Nuevo Madero 23/07/2009). En junio de 2008 la misma parcela 10 fue nuevamente vendida a la desarrolladora Creaurban por un total de 35 millones de dólares ${ }^{14}$. Vale decir que en el transcurso de apenas tres años el predio en cuestión por lo menos triplicó su valor. El proyecto Art Maria planificado por Creaurban para la parcela 10 mantiene la volumetría aprobada en el anterior proyecto +5411 . Una de las torres, destinada a viviendas para el exclusivo segmento $\mathrm{ABC} 1$, ya estaba vendida en un $100 \%$ y en dicha venta quedaron incluidos los compradores de la etapa +5411 . Otra de las torres alberga un Hotel "boutique" pero de escala reducida y gran parte del proyecto será tratado a la manera de "un Rockefeller Center", como lo describió Saenz Valiente “en el que el uso que reinará será el de oficinas; pensadas para un inversor del exterior que se interesa por el negocio de renta".

Parcelas 1, 2 y 3. Hacia 2005 las parcelas 1, 2 y 3 del Dique $1\left(50.000 \mathrm{~m}^{2}\right)$ fueron vendidas a la desarrolladora Vizora, perteneciente al Grupo Banco Macro, por un valor de 40 millones de dólares. Luego de asociarse con el empresario inmobiliario Fernández Prieto (quien adquirió un 25\% del terreno) en el año 2007 se inició la construcción del proyecto que se compone de cinco torres para usos residenciales y de oficinas. Junto con la construcción se inició la preventa de los inmuebles.

Parcelas 12 y 13. En las parcelas 12 y 13 del Dique 1, que ocupan una superficie de $80.000 \mathrm{~m}^{2}$, se está construyendo el proyecto denominado Madero Harbour. Este proyecto está en manos de la desarrolladora GNVGroup (ex Newside). Se trata de un proyecto que incluye residencias, oficinas y equipamiento urbano y de servicios. Contempla: un centro comercial con más de 150 locales, dos tiendas departamentales, un supermercado, homecenter, 10

14 La desarrolladora Creaurban cuenta con participación en varios proyectos en Puerto Madero: edificio Madero Plaza, Torres Mulieris y Torres del Yacht. El proyecto planificado para la parcela 10 se denomina Art Maria. Durante la presentación del proyecto se señaló que se mantendrá la volumetría aprobada en el proyecto 5411 . De este modo, una de las torres se destinará a viviendas segmento $\mathrm{ABC} 1$, de la cual ya está vendida el $100 \%$ y en la cual quedaron incluidos los compradores de la etapa +5411 ; otra de las torres albergará un Hotel "boutique" pero de escala reducida y gran parte del proyecto será tratado a la manera de "un Rockefeller Center", como lo describió Saenz Valiente "en el que el uso que reinará será el de oficinas, pensadas para un inversor del exterior que se interesa por el negocio de renta”. 
salas de cine para 1.600 espectadores, un hotel boutique de 5 estrellas de 140 habitaciones, centro médico con consultorios externos, spa para tratamientos estéticos con salones de belleza, 40 estudios lofts, dos torres de apart hotel, un edificio de oficinas con helipuerto, cocheras y estacionamiento para más de 3.000 vehículos, un amplio espacio público que se denominará Plaza de las Artes, un complejo deportivo y un edificio para la Prefectura Naval. Ya se han comenzado a construir los dos primeros edificios de oficinas (uno de ellos ya se encuentra terminado) y el primer edificio de departamentos (en este caso se trata de studios de 1 y departamentos de 3 ambientes) ${ }^{15}$.

nota:

El grisado del cuadro corresponde a las operaciones realizadas por la empresa Newside: (i) compra de todo el dique; (ii), (iv) y (vi) venta de tres parcelas. Quedaría aún sin venderse un predio de $60.000 \mathrm{~m}^{2}$.

FUENTES

I Reporteinmobiliario.com. (Lunes 11 de Junio de 2007). De Aranalfe a Newside.

iI Diario Clarín. (13/7/2001). Nuevos proyectos a orillas Del Río. HTtP://EDant.Clarin.COM/SUPLEMENTOS/ARQUITECTURA/2001/08/20/A-00201.HTM

iII Diario El Cronista: (http://www.Cronista.com/notas/109616-Mayan\%Puerto-Madero).

IV Nuevo Madero. (23/07/2008).

V Nuevo Madero. (27/07/2008).

vi PÁgina Web de la desarrolladora Vizora

\section{La promoción inmobiliaria como fuente de valorización del suelo: desarrolladores} emprendedores y marketing estratégico

La promoción inmobiliaria contribuyó de modo importante a la valorización del suelo en Puerto Madero, permitiendo a un conjunto de nuevos propietariosdesarrolladores captar enteramente esos incrementos. Es interesante constatar de qué manera, sin llegar a concretarse las obras, el posicionamiento en el mercado de inmuebles proyectados a futuro funcionó como si los edificios ya estuvieran construidos y vendidos. En eso consiste el marketing estratégico en el negocio inmobiliario: lograr que un producto se venda por el valor de lo percibido, por "beneficios" económicos, funcionales o emocionales que van más allá del costo de adquisición y producción.

Esta capacidad de "crear valor" mediante la gestión y venta de proyectos recayó en la figura de desarrolladores emprendedores. La literatura especializada describe a los desarrolladores (developers) como agentes del mercado inmobiliario que conjugan varios perfiles: detectan el negocio, lo estructuran, consiguen el financiamiento o lo aportan con capital propio, llevan adelante la obra y comercializan el producto final. Son caracterizados como hombres de negocios emprendedores (típicamente arquitectos, ingenieros, brokers inmobiliarios, eventualmente abogados o contadores), con intuición suficiente como para anticipar los cambios urbanos y las tenden-

Entrevista a Alejandro Ginevra en Reporte Inmobiliario "De Aranalfe a Newside" 11 de junio de 2007 http://www. reporteinmobiliario.com/nuke/article944-de-aranalfe-a-newside.html y Entrevista a Alejandro Ginevra a cargo GNV Group. Reporte Inmobiliario 18 de Marzo de 2010 http:/ $/$ www.reporteinmobiliario.com/nuke/ modules.php?name $=$ News\&file=article\&sid $=1612$ 
cias en el mercado, con capital propio o de terceros, con capacidad empresaria, creatividad, convicción y habilidad de negociación. Los desarrolladores emprendedores son quienes pueden transformar un pantano un distrito de lujo ${ }^{16}$.

El auge de los desarrolladores en Puerto Madero (así como en el resto de Argentina) reflejó una tendencia mundial en la que el real estate pasó a ser considerado un sector privilegiado para rentabilizar o resguardar el capital. Esta tendencia se vio reforzada en el país porque buena parte del ahorro de sectores medios y medios altos que antes de 2001 se dirigía hacia los bancos- comenzó a fluir de manera progresiva hacia los emprendimientos inmobiliarios. Después de la crisis de 2001 ha ocurrido lo que algunos analistas llaman una "tergiversación de la percepción del riesgo":

Con razón o sin ella, un plazo fijo en una entidad de primera línea internacional es visto como algo menos atractivo y quizás más riesgoso que un boleto de compra venta en un edificio en construcción (Tabakman, 2006, p. 34).

El caso de la reventa de la Parcela 10 del Dique 1 sirve nuevamente para ilustrar el modo de operar de la promoción inmobiliaria. Como se mencionó antes, dicha parcela había sido comprada en 2001 por la desarrolladora G\&D a 10,5 millones de dólares y vendida tres años después a Creaurban por 35 millones. ¿Cuál fue la fuente de estas plusvalías urbanas, cercanas a los 25 millones de dólares?

Los operadores del mercado reconocen que el "valor agregado al suelo" por G\&D consistió en el proyecto +5411 , una vez cerrado. Es decir: un proyecto edilicio aprobado por el municipio y posicionado en el mercado, con la incorporación de un arquitecto de prestigio internacional, una cadena hotelera de nivel mundial y decenas de ventas de unidades concretadas. Según testimonios del directivo de la empresa, todo eso, junto con las obras de infraestructura y apertura de calles, que se habían promovido en el Dique 1, dio lugar a la posibilidad de hacer esa transacción del suelo sin llegar a hacer obras concretas en el área ${ }^{17}$.

Según los analistas inmobiliarios que entrevistaron al directivo de G\&D:

La empresa tuvo la audacia, la visión, y convocó a inversores que creyeron en ellos por su amplia experiencia como arquitectos y desarrolladores, con actividad en Buenos Aires y el exterior. $\mathrm{Y}$ a través de un fideicomiso pusieron en marcha el proyecto. (...) El enorme trabajo que realizaron los desarrolladores desde que adquirieron el lote hasta que apareció la oferta de compra, consistió no sólo en hacer y aprobar un proyecto e invertir en marketing y publicidad. También implicó concretar decenas de ventas de unidades. No hay ninguna duda que lo que han hecho los developers se llama 'desarrollar'. Lo que esta gente está concretando es la esencia de la actividad de un emprendedor: comprar bien un terreno, agregarle valor y realizar la ganancia. Saber cuándo salir es clave en este negocio ${ }^{18}$.

Más allá de esta descripción personalizada, en Puerto Madero quienes llevan adelante ese conjunto de actividades son empresas. Cuando las empresas despliegan todas las funciones mencionadas suele denominarse "desarrolladora integral". Este tipo de empresas suele estar asociada con otras similares para expandir su escala o capacidad de operación en otras ciudades o países. A veces también crea su propio departamentos o empresa especializada en comercialización y/o consultoría que trabaja para la firma madre y para terceros.

17 http://www.reporteinmobiliario.com/nuke/article1210-reunion-de-referentes.html

18 http://www.reporteinmobiliario.com/nuke/article1142-la-historia-real-de-5411.htm. 
A partir de esta visión y presentación del tema, se deriva una cuestión importante a remarcar desde el punto de vista de una política empresarialista más progresista que apuntara a una distribución equitativa de costos y beneficios entre el sector público y el privado. Tanto en el discurso del desarrollador como en el del analista hay un reconocimiento explícito de que parte del "valor agregado al suelo" en la parcela 10 es atribuible a la aprobación del proyecto y la provisión de infraestructura en el área. Se trata en ambos casos de actuaciones a cargo de la Corporación y del Municipio, y no del desarrollador. Sin embargo, esa plusvalía que resulta imputable directamente a actuaciones públicas no fue recuperada y tampoco reclamada (al menos por la via de instrumentos formales) por la Corporación. Y cabe la duda acerca de si el desarrollador hubiera estado dispuesto a pagar una contribución en caso de que el Municipio se lo hubiera exigido mediante instrumentos fiscales específicos.

Finalmente, se podría agregar que este tipo de agentes que se describen como emprendedores no han arriesgado demasiado, ya que no llegaron a invertir capital en la construcción. Para los que sí construyeron, el riesgo estuvo ante la posibilidad de que finalmente los inmuebles no pudieran venderse. Sin embargo, los edificios se vendieron de antemano. Es decir, que la gestión inmobiliaria exitosa es la que logró captar fondos de terceros para "fondear el negocio" minimizando el uso de capital propio. Quienes arriesgaron fueron los inversionistas que compraron "en pozo" (antes que la obra se haya iniciado), por supuesto que también especulando con la posibilidad de obtener rentas elevadas en tiempos cortos.

\section{Reflexión final. La corporación: ęéxito o fracaso?}

Los defensores de Puerto Madero sostienen que la crítica a este proyecto se centra sobre la acción y que rara vez se miden los efectos de la inacción. Tienen razón. En este sentido, hay que reconocer que Puerto Madero ha significado la puesta en marcha de un proyecto ambicioso de urbanización y desarrollo inmobiliario que logró realizarse, lo cual no es poco en un país descreído de la labor del Estado como motor de emprendimientos económicamente rentables. Puerto Madero ha permitido la puesta en valor de un área degradada. $Y$ de no haberse conseguido atraer la inversión privada, mediante una gestión sin duda emprendedora en cuanto a la lógica estatal aplicada, el área posiblemente continuaría en retroceso.

Las objeciones que se derivan del análisis que acá se ha realizado no son de naturaleza ideológica sino política: la Corporación subvencionó con recursos públicos a inversores privados y consumidores de altos ingresos, incluyendo en este universo una gama de empresas y agentes que obtuvieron enormes beneficios mediante prácticas especulativas de suelo urbano.

El discurso de que la operación se hizo "sin costo para el Estado", luego transformada en "sin utilizar recursos del Estado" esencialmente no es cierta. Se usaron tierras estatales estratégicas para obtener recursos que debieron ser aplicados para la financiación de infraestructura en la misma área, para el sostenimiento de la burocracia de la Corporación y el mantenimiento de un barrio de lujo. La aplicación de 
los dividendos públicos para usos sociales, con fines redistributivos, tal como estaba originalmente previsto, no se concretó.

Para lograr tal objetivo, la Corporación debió haber exigido a los agentes privados, que se beneficiaron con la operación urbanística e inmobiliaria, reintegrar al sector público una parte de los beneficios generados a través de actuaciones públicas y privadas. Una medida de ese tipo nutre los principios de política urbana conocidos como "recuperación de plusvalías urbanas" o "participación en plusvalías urbanas" o "gestión social de la valorización del suelo"; todos ellos aluden a la regulación que debe hacer el poder público para recuperar para la colectividad parte de la valorización de la tierra promovida por las acciones públicas o privadas -obras públicas, cambios en el uso del suelo o en la clasificación del suelo- y que son absorbidas en forma privada (Santoro, Furtado, Leiva, Smolka y Cymbalista, 2005).

Hay que recordar que han cambiado las condiciones del contexto en el que se gestó Puerto Madero, con crisis económica, pleno auge de las políticas neoliberales, debilidad de la autoridad portuaria y flexibilización de todas las regulaciones estatales que permitieron la transferencia de las tierras nacionales a la Corporación sin necesidad de una ley nacional aprobada por el Congreso de la Nación. Parece entonces saludable revisar críticamente algunos principios de la política empresarialista de Puerto Madero para avanzar a futuro en una política urbana más equitativa y progresista. IEURE

\section{Referencias bibliográficas}

Auditoría General de la CABA. (2003). Informe Final de Auditoría. Corporación Antiguo Puerto Madero, Buenos Aires.

Auditoría General de la CABA. (2005). Informe de Relevamiento Corporación Antiguo Puerto Madero S.A. Buenos Aires.

Borja, J. \& Castells, M. (1997). Local y global, La gestión de las ciudades en la era global. Madrid: Taurus. Corporación Antiguo Puerto Madero S.A. Memoria y Estados Contables al 31 de diciembre de 2009 presentados en forma comparativa. En: www.puertomadero.com

Cuenya, B. (2009). Grandes proyectos urbanos, cambios en la centralidad urbana y conflicto de intereses. Notas sobre la experiencia argentina. Ponencia presentada en Congreso Latin American Studies Association, Rio de Janeiro, Brasil.

De Mattos, C. (2009). Modernización capitalista, Metamorfosis Urbana y Competitividad en América Latina. Ponencia presentada en Seminario Internacional La Investigación Urbana: Perspectivas y Desafíos, Lima, Perú. www.uarm.edu,pe/Docs/investigacion/.../competitividad_mattos.pdf

Diario El Cronista (10/6/2009). Se construirá en Puerto Madero uno de los hoteles más lujosos del mundo. (http://www.cronista.com/notas/109616-Mayan\%Puerto-Madero).

Diario La Nación (15/9/2009). Se demoran inversiones en turismo.

Etulain, C. (2009). Gestión urbanística y proyecto urbano. Modelos y estrategias de intervención. Buenos Aires: Nobuko. 
Garay, A. (2001). Acerca de la gestión de proyectos urbanos: la enseñanza de Puerto Madero. Trabajo presentado para una publicación de la escuela de Arquitectura de Harvard, USA (mimeo).

Harvey, D. (2007). De la gestión al empresarialismo: la transformación de la gobernanza en el capitalismo tardío. En D. Harvey (Ed.). Espacios del capital. Madrid: Aikal.

Jaramillo, S. (2003). Los fundamentos económicos de la Participación en Plusvalias. Bogotá y Cambridge: Ed. Universidad de los Andes y Lincoln Institute of Land Policy.

J.L. Ramos Brokers Inmobiliarios (2009). Informe sobre Puerto Madero, el barrio más joven de la ciudad. La segunda globalización de Buenos Aires. Informe del Mercado Inmobiliario, Número Especial, junio, Buenos Aires.

Jurado, M. (13/7/2001). Nuevos proyectos a orillas del río. Diario Clarin http://edant.clarin.com/ suplementos/arquitectura/2001/08/20/a-00201.htm

Nuevo Madero (23/07/2008). Se concretó la venta de +5411. http://www.nuevopuertomadero. com/?Se_concreto_la_venta_de_5411\&page $=$ ampliada\&id $=377$

Nuevo Madero (27/07/2008). Se convretó la venta de +5411 .

Nuevo Madero (10/2/2009). Reportaje al Arq. Alfredo Garay, Director de la Corporación Puerto Madero. http://www.nuevomadero.com/esp/vivir...id_noticia $=430$

OECD Territorial Reviews (2007). Competitive Cities: A New Entrepreneurial Paradigm in Spatial Development, www.oecd.org/bookshop

Puerto Madero, sitio web, www.puertomadero.com

Rodríguez, A.; Moulaert, F. \& Swyngedow, E. (2001). Nuevas políticas urbanas para la revitalización de las ciudades en Europa. Ciudad y Territorio, Estudios territoriales, XXXIII No. 129, Madrid, pp. 409-424.

Reporte Inmobiliario (18/03/2010). Buenos Aires.

Reporte Inmobiliario (11/6/2007). De Aranalfe a Newside. Buenos Aires.

Santoro, P. (Ed.); Furtado, F.; Liva, M.; Smolka, M. \& Cymbalista, R. (2004). Gestao social da valorizaçao da terra. Caderno Polis 9, Sao Paulo.

Tabakman, D. et al. (2006). Desarrollos inmobiliarios exitosos. Buenos Aires: Ediciones BRE.

Topalov, C. (1984). Ganancias y rentas urbanas. Elementos teóricos. Madrid: Siglo XXI Editores SA. 